\title{
Identification of a Motif in the Acetylcholine Receptor $\beta$ Subunit Whose Phosphorylation Regulates Rapsyn Association and Postsynaptic Receptor Localization
}

\author{
Lucia S. Borges, ${ }^{1 \star}$ Sergey Yechikhov, ${ }^{1 *}$ Young I. Lee, ${ }^{1}$ John B. Rudell, ${ }^{1}$ Matthew B. Friese,,${ }^{2}$ Steven J. Burden, ${ }^{2}$ and \\ Michael J. Ferns ${ }^{1}$ \\ ${ }^{1}$ Departments of Anesthesiology and Physiology and Membrane Biology, University of California, Davis, Davis, California 95616, and ${ }^{2}$ Molecular \\ Neurobiology Program, Skirball Institute of Biomolecular Medicine, New York University Medical School, New York, New York 10016
}

\begin{abstract}
At the neuromuscular junction, the acetylcholine receptor (AChR) is specifically clustered in the postsynaptic membrane via interactions with rapsyn and other scaffolding proteins. However, it remains unclear where these proteins bind on the AChR and how the interactions are regulated. Here, we define a phosphorylation-dependent binding site on the receptor that mediates agrin-induced clustering. Using chimeric proteins in which $\mathrm{CD} 4$ is fused to the large intracellular loop of each of the AChR subunits we found that agrin induced clustering of only chimeras containing the $\beta$ subunit loop. By making deletions in the $\beta$ loop we defined a 20 amino-acid sequence that is sufficient for clustering. The sequence contains a conserved tyrosine (Y390) whose phosphorylation is induced by agrin and whose mutation abolished clustering of $\beta$ loop chimeras and their ability to inhibit agrin-induced clustering of the endogenous AChR. Phosphorylation of the AChR $\beta$ subunit is correlated with increased rapsyn/AChR binding, suggesting that the effect of $\beta Y 390$ phosphorylation on clustering is mediated by rapsyn. Indeed, we found that rapsyn associated with CD4- $\beta$ loop chimeras in a phosphorylation-dependent manner, and that agrin increased the ratio of rapsyn binding to wild type $\mathrm{AChR}$ but not to $\mathrm{AChR}-\beta^{3 \mathrm{~F} / 3 \mathrm{~F}}$, which lacks $\beta$ loop tyrosine phosphorylation sites. Together, these findings suggest that agrin-induced phosphorylation of the $\beta$ subunit motif increases the stoichiometry of rapsyn binding to the AChR, thereby helping to stably cluster the receptor and anchor it at high density in the postsynaptic membrane.
\end{abstract}

Key words: synaptogenesis; neuromuscular junction; nicotinic acetylcholine receptor; phosphorylation; postsynaptic membrane; agrin

\section{Introduction}

Rapid signaling at neuronal synapses is mediated by ligand-gated ion channels, which are concentrated in the postsynaptic membrane beneath the nerve terminal. As the density of neurotransmitter receptors is a key determinant of synaptic strength and function, the specific localization of receptors is critical for synapse formation, maintenance and plasticity. Receptor localization is mediated by direct and indirect interactions with scaffolding proteins that link the receptors to the postsynaptic cytoskeleton, with these interactions being regulated by specific trans-synaptic signals (Sheng and Pak, 2000; Sanes and Lichtman, 2001). For example, at the developing neuromuscular junction, agrin, a motoneuron-derived factor, is required for stable aggregation of acetylcholine receptor (AChR) at nascent synaptic contacts, counter-acting the activity-driven dispersal of AChR

Received June 3, 2008; revised Sept. 10, 2008; accepted Sept. 22, 2008.

This work was supported by National Institutes of Health Grants NS049354 to M.J.F. and NS36193 to S.J.B., and was also conducted in a facility constructed with support from Research Facilities Improvement Program Grant Number C06 RR17348-01 from the National Center for Research Resources, National Institutes of Health. We thank Sheridan Swope (formerly of Georgetown University) for the $\beta$ subunit phospho-specific antibody and Zach Hall for helpful comments on this manuscript.

*L.S.B. and S.Y. contributed equally to this work.

Correspondence should be addressed to Dr. Michael J. Ferns, Department of Physiology and Membrane Biology, University of California, Davis, One Shields Avenue, Davis, CA 95616. E-mail: mjferns@ucdavis.edu.

DOI:10.1523/JNEUROSCI.2508-08.2008

Copyright $\odot 2008$ Society for Neuroscience ～0270-6474/08/2811468-09\$15.00/0 that eliminates aneural aggregates (Lin et al., 2005; Misgeld et al., 2005). Indeed, in agrin-null mice, AChR aggregates are largely eliminated by birth, resulting in perinatal lethality (Gautam et al., 1996). Agrin localizes the AChR by signaling via the musclespecific kinase (MuSK) and components of its signaling pathway have only recently been identified (Strochlic et al., 2005; Okada et al., 2006). The mechanism by which MuSK signaling regulates the interaction of the AChR with scaffolding proteins that localize it in the postsynaptic membrane, however, remain unknown.

The muscle AChR is a pentamer of homologous subunits, with the stoichiometry $\alpha(2), \beta, \delta$ and $\gamma$ (fetal) or $\varepsilon$ (adult) subunits. Each subunit has a large intracellular loop between the third and fourth transmembrane domains that is the likely site for regulated interactions with postsynaptic scaffolding proteins. Indeed, we have shown previously that mutation of a tyrosine phosphorylation site in the long cytoplasmic loop of the $\beta$ subunit impairs agrin-induced cytoskeletal anchoring and aggregation of mutant AChR in muscle cells (Borges and Ferns, 2001). Moreover, in mice lacking all tyrosines in the $\beta$ subunit intracellular loop, neuromuscular junctions are simplified and reduced in size (Friese et al., 2007). The most prominent scaffolding protein is rapsyn, which colocalizes precisely with the AChR at developing neuromuscular junctions (Froehner et al., 1981; Burden, 1985; Noakes et al., 1993) and at agrin-induced clusters in cultured myotubes (Wallace, 1989). Rapsyn aggregates the AChR when 
A
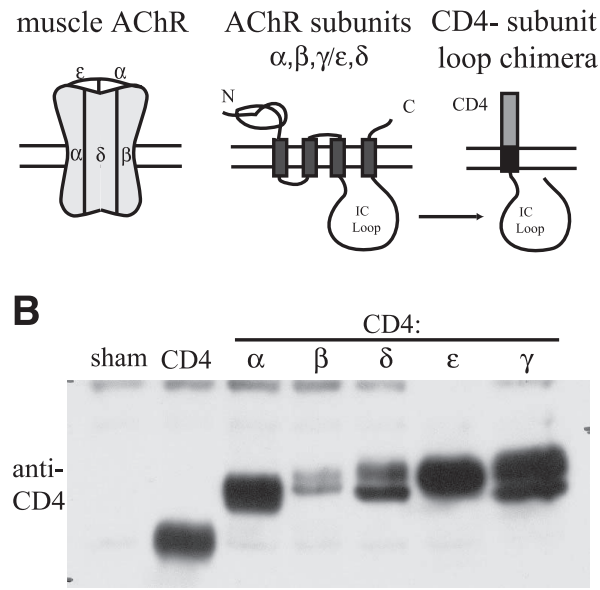
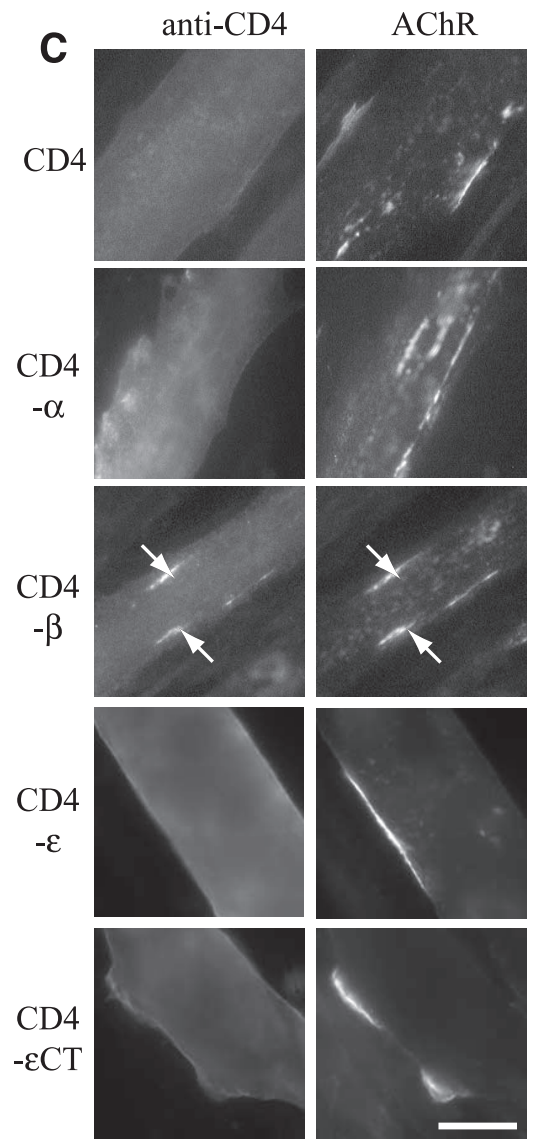

Figure 1. CD4 chimeras containing the $\beta$ subunit intracellular loop cocluster with the AChR. $\boldsymbol{A}$, Schematic showing construction of chimeric proteins, in which the CD4 extracellular and transmembrane domains were fused with the major intracellular (IC) loop of each AChR subunit. $B, C D 4$-subunit loops were expressed transiently in Sol 8 myotubes and then immunoprecipitated from cell extracts and immunoblotted with an antibody to the CD4 extracellular domain. All CD4-subunit loop chimeras were robustly expressed. C, Sol8 myotubes transfected with CD4-subunit loop chimeras were treated with agrin for $16 \mathrm{~h}$, and then immunostained for surface CD4 and AChR. Only CD4- $\beta$ loop coclustered with the AChR in response to agrin treatment (arrows). CD4 and all other CD4-subunit loops remained diffusely distributed on the myotube surface (CD4- $\gamma$ and $\delta$ loops are not shown, but see Table 1). CD4- $\varepsilon$ CT denotes an additional chimera that includes the IC loop, fourth transmembrane domain and C terminus, which also failed to cluster. Scale bar, $20 \mu \mathrm{m}$.

they are coexpressed in heterologous cells (Froehner et al., 1990; Phillips et al., 1991), and the AChR fails to cluster at neuromuscular synapses in rapsyn null mice (Gautam et al., 1995). However, neither the site of rapsyn binding by the AChR nor the factors regulating binding to it are known. In addition, the tumor suppressor APC plays a role in AChR clustering (Wang et al., 2003), and other scaffolding and adaptor proteins may also bind and help localize the AChR. To identify protein interaction domain(s) responsible for AChR localization, we have screened for subunits and domains of the AChR that mediate receptor clustering. Using chimeric proteins consisting of CD4 fused to each of the AChR subunit intracellular loops, we identify a 20 amino acid sequence in the $\beta$ subunit loop that is sufficient for clustering. Moreover, we show that agrin-induced phosphorylation of this motif regulates rapsyn interaction with the $\mathrm{AChR}$ and receptor localization.

\section{Materials and Methods}

Cell culture and transfection. Sol8 and C2 mouse muscle cells were maintained in growth medium consisting of DMEM-HI, supplemented with $20 \%$ fetal bovine serum, $100 \mathrm{U} / \mathrm{ml}$ penicillin-streptomycin, and $2 \mathrm{~mm}$ L-glutamine. For immunostaining experiments, the cells were grown on 8 -well chamber slides (Nalge Nunc Inc.), precoated with $0.1 \%$ Gelatin in the case of Sol8 cells (w/v; Fisher Scientific), and the myoblasts were transfected at $\sim 90 \%$ confluence using Fugene (Roche). Cells were then incubated with fusion medium (DMEM-HI supplemented with 5\% horse serum and $2 \mathrm{~mm}$ L-glutamine) to induce formation of myotubes. For biochemical experiments, cells were grown in $10 \mathrm{~cm}$ dishes and transfected using the $\mathrm{CaPO}_{4}$ method. Immortalized muscle cell lines generated from wild type and AChR- $\beta^{3 \mathrm{~F} / 3 \mathrm{~F}}$ mice carrying the $\mathrm{H}-2 \mathrm{~Kb}$-tsA58 transgene were grown as described previously (Friese et al., 2007).

CD4-subunit loop constructs. To generate CD4-subunit loop chimeras, a BglII site was introduced by site directed mutagenesis at the end of the transmembrane domain of mouse CD4. The intracellular domain of CD4 was then excised and PCR fragments comprising each of the AChR subunit loops were ligated into this site. To generate $\mathrm{CD} 4 \mathrm{ct}-\beta$ loop fragments, a $B g$ III site was introduced at the $\mathrm{COOH}$ end of the CD4 intracellular domain and PCR fragments comprising segments of $\beta$ loop were ligated into this site. This CD4 tail spacer was used to position the short $\beta$ loop sequences further from plasma membrane. PCR based mutagenesis was performed to replace the $\beta$-subunit loop tyrosine-390 residue with a phenylalanine (Y390F) using the QuickChange kit (Stratagene). All of the CD4/loop chimeras were constructed in a pUC-CD4 vector and then subcloned into the mammalian expression vector pcDNA3 and confirmed by sequencing.

Immunostaining and clustering assay. For immunostaining of transfected Sol8 and C2 muscle cells, surface $\mathrm{AChR}$ and $\mathrm{CD} 4$ chimeras were detected by incubating live myotubes with Alexa 594-conjugated $\alpha$-bungarotoxin (InvitrogenMolecular Probes) and anti-CD4 antibody H129.19 (BD Biosciences-PharMingen) for 15 $\mathrm{min}$. After washing, the myotubes were fixed with $2 \%$ paraformaldehyde for $20 \mathrm{~min}$, blocked with serum, and then incubated with Alexa 488conjugated anti-rat secondary antibody. Identical results were obtained using either Sol8 or $\mathrm{C} 2$ myotubes, and when the transfected cultures were fixed before antibody labeling. The labeled culture slides were viewed with a Zeiss Axioplan 2 IE fluorescence microscope and Plan-Apo $63 \times$ oil objective (NA 1.40), and digital images acquired using an Axiocam MRM camera and Axiovision software. In some experiments, we also used a Nikon Eclipse E600 microscope, CFI Plan Apo 60× oil objective (NA 1.4), and Optronics camera. To quantify agrin-induced clustering of $\mathrm{CD} 4$-subunit loops, we selected random fields and then scored all CD4-positive myotubes according to whether or not they had surface CD4 clusters colocalizing with AChR clusters. The counts were made from 3 to 6 experiments for each CD4-AChR subunit loop chimeric protein.

For the competition experiment, we used C2 myotube cultures and quantified agrin-induced clustering by selecting random fields and then counting the number of AChR clusters in $125 \mu \mathrm{m}$ segments of all CD4positive myotubes. All transfected cultures were coded and counted blind. The number of clusters per myotube segment was normalized to that in $\mathrm{CD} 4$ expressing myotubes for each experiment and data collected from 8 independent experiments.

Protein extraction, immunoprecipitation and Western blotting. To assay expression of $\mathrm{CD} 4$ chimeras by Western blotting, transfected muscle cells were washed, scraped off and pelleted in ice-cold PBS. They were then re-suspended in extraction buffer (0.5\% Triton X-100, 25 mM Tris, 25 mм glycine, $150 \mathrm{~mm} \mathrm{NaCl}, 5 \mathrm{~mm}$ EDTA and the protease inhibitors PMSF, benzamidine, $\mathrm{N}$-ethylmaleimide, and $\mathrm{Na}_{2} \mathrm{~S}_{4} \mathrm{O}_{6}$ ) and incubated for $10 \mathrm{~min}$ on ice, after which the insoluble proteins were pelleted by 
centrifugation at 13,000 rpm for $5 \mathrm{~min}$. The CD4 chimeras were immunoprecipitated from the soluble fraction with monoclonal antibody GK1.5 (BD Biosciences-PharMingen) chemically cross-linked to protein G-agarose (Invitrogen). After resuspending and boiling in $2 \times$ protein loading buffer (SDS, glycerol, $10 \% \beta$-mercaptoethanol and bromphenol blue), the samples were separated on $10 \%$ polyacrylamide gels and immunoblotted with monoclonal antibody H129.19 against CD4, followed by HRP-conjugated anti-rat secondary antibody (Amersham) and visualization with enhanced chemiluminescence. Expression of CD4 $\beta$ loop fragments was also assayed in some cases by immunoblotting with mAb124, which recognizes an epitope in the $\beta$ subunit loop Y390 region. To assay phosphorylation of CD4- $\beta$ loop chimeras, we immunoblotted with a rabbit polyclonal antibody specific for phosphorylated $\beta$-subunit Y390 residue (JH-1360) (Gillespie et al., 1996).

For the competition experiments, we immunoprecipitated the CD4chimeras (CD4- $\beta 370-406$, and CD4ct- $\beta 382-401$ ) as described above and then sequentially isolated the AChR using biotinylated $\alpha$-bungarotoxin and streptavidin-agarose (Invitrogen). The isolates were then immunoblotted with antibodies to the $\beta$-subunit Y390 region (mAb124) and to CD4. Blotting with mAb124 showed the relative expression of the chimeric constructs to that of the endogenous AChR $\beta$ subunit.

To assay rapsyn association with AChR, surface AChR was labeled with biotinylated $\alpha$-BuTX and isolated from cell extracts using avidin beads (Invitrogen-Molecular Probes). To detect coimmunoprecipitated rapsyn, we immunoblotted with polyclonal antibody B6766, and the blots were reprobed with phospho-specific $\beta$ Y390 antibody (JH-1360) and with anti-AChR $\alpha$ subunit antibody (mAb210). In some experiments, phosphorylated AChR was selectively immunoprecipitated using phospho-specific $\beta Y 390$ antibody (JH-1360) chemically cross-linked to Protein $\mathrm{G}$ agarose beads and the remaining surface AChR was isolated using biotinylated $\alpha$-BuTX. Both isolates were then immunoblotted with anti-rapsyn antibody B6766, anti-phosphotyrosine antibodies $4 \mathrm{G} 10$ and PY20, and anti-AChR $\alpha$ subunit antibody mAb210. In a reverse approach, rapsyn was immunoprecipitated with polyclonal anti-rapsyn antibodies B5668 and B6766 (generated against amino-acids 133-153 and 402-412 of rapsyn, respectively) (Lee et al., 2008), and associated AChR was detected by immunoblotting with anti-AChR $\alpha$ subunit antibody (mAb210). To assay rapsyn association with the $\beta 382-401$ motif, C2 muscle cells stably expressing CD4ct- $\beta 382-401$ Y390 or Y390F were treated with agrin or agrin $(500 \mathrm{pm})$ plus pervanadate $(0.2 \mathrm{~mm})$ for $1 \mathrm{~h}$. After detergent extraction, the CD4 chimeras were immunoprecipitated and immunoblotted for rapsyn as described above. The blots were reprobed with mAb124 to detect the $\beta$ subunit motif and with JH-1360 to detect phosphorylated Y390. We also sequentially isolated AChR from the same lysates to confirm receptor levels (mAb210) and $\beta$-subunit phosphorylation (JH-1360).

The intensity of the Western blot signals was quantified using ImageGauge V4.22 software (FujiFilm). To average several experiments, the integrated intensity of bands was expressed as a percentage of the value obtained in wild type, untreated cells. In experiments assaying rapsyn/AChR association, the data were also normalized to the level of AChR or rapsyn that was immunoprecipitated. Averages were calculated from 6 independent experiments and statistical significance determined using the Student's $t$ test.

Rapsyn overlay blots. GST-fusion proteins were constructed in pGEX4T3 consisting of GST, the CD4 tail linker (ct) and $\beta 382-401$ Y390 or Y390F. These constructs were expressed in the TKB1 bacterial strain, which is a BL21 derivative with an inducible tyrosine kinase expressed under a tryptophan promoter. GST and GST-rapsyn were expressed in the BL21 strain. Fusion proteins were extracted in Sarkosyl and isolated on glutathione beads (as described by Frangioni and Neel, 1993), and protein concentrations were determined on Coomassie-stained gels using BSA standards. For overlays, $\sim 3 \mu \mathrm{g}$ of each fusion protein were separated on $10 \%$ SDS-PAGE gels, transferred onto PVDF membrane and incubated with $5 \mu \mathrm{g}$ of GST-rapsyn in Tris buffer containing $4 \%$ Blotto and $0.1 \%$ Triton X-100. Bound probe was then detected by immunoblotting with polyclonal anti-rapsyn antibody B5668. In blocking experiments, the GST-rapsyn probe was incubated together with $25 \mu \mathrm{g}$ of soluble GSTct $\beta 382-401$ Y390 or Y390F. To estimate the level of GSTct $\beta 382-401$ Y390 phosphorylation, we immunoprecipitated with
Table 1. Quantification of agrin-induced clustering of CD4-subunit loops and $\beta$ loop fragments

\begin{tabular}{llcc}
\hline CD4-chimera & $\begin{array}{l}\text { No. of } \\
\text { experiments }\end{array}$ & $\begin{array}{l}\text { No. of } \\
\text { myotubes counted }\end{array}$ & $\begin{array}{c}\text { \% myotubes } \\
\text { with clusters }\end{array}$ \\
\hline CD4 & 5 & 80 & 1 \\
CD4- & & & \\
$\alpha$ loop & 5 & 88 & 0 \\
$\beta$ loop & 6 & 94 & 73 \\
$\gamma$ loop & 3 & 57 & 0 \\
$\delta$ loop & 5 & 63 & 3 \\
$\epsilon$ loop & 5 & 75 & 0 \\
$\beta 333-406$ & 6 & 117 & 74 \\
$\beta 407-469$ & 5 & 84 & 2 \\
$\beta 333-406 / \epsilon$ & 6 & 111 & 77 \\
$\beta 370-406$ & 3 & 60 & 45 \\
$\beta$ loop Y390F & 6 & 100 & 1 \\
$\beta 333-406$ Y390F & 3 & 57 & 2 \\
$\beta 333-406 / \epsilon$ Y390F & 3 & 53 & 0 \\
$\beta 370-406$ Y390F & 3 & 60 & 3 \\
CD4ct- & & & 88 \\
$\beta 382-401$ & 3 & 60 & 15 \\
$\beta 382-401$ Y390F & 3 & 60 & 5 \\
$\beta 385-396$ & 3 & 60 & 22 \\
$\delta 385-404$ & 3 & & \\
\hline
\end{tabular}

CD4-chimera-positive myotubes were identified in random fields and scored for the presence or absence of CD4 clusters that colocalized with AChR clusters. Agrin induced robust clustering of CD4- $\beta$ loop chimeras encompassing amino acids 382401 , with $45-88 \%$ of the expressing myotubes having clusters. Mutation of $\mathrm{Y} 390$ abolished clustering of these constructs, and all other CD4-loops showed background or weak colocalization with AChR clusters.

phospho- $\beta$ Y390 antibody and then compared the amount of immunoprecipitated versus residual fusion protein by immunoblotting with antiGST antibody; this indicated that $\sim 25-50 \%$ is phosphorylated.

\section{Results}

\section{Identification of AChR subunit intracellular loop domains} sufficient for clustering

Direct and indirect interactions with scaffolding proteins are thought to localize the AChR in the postsynaptic muscle membrane (Banks et al., 2003); however, the relevant binding sites that mediate such interactions and the factors that regulate binding are poorly defined. To identify the domains in the AChR that mediate its synaptic localization, we generated chimeric constructs in which the CD4 extracellular and transmembrane domains were fused with the major intracellular loops of each of the AChR subunits (Fig. 1A). This allowed surface expression and enabled us to test each subunit loop individually and determine whether it contains motifs involved in agrin-induced clustering of the receptor. To first confirm expression, the CD4-subunit chimeras were expressed in Sol8 myotubes by transient transfection and then immunoprecipitated and immunoblotted using an antibody to the CD4 extracellular domain (Fig. $1 B$ ). We found that all of the CD4-loop chimeras were robustly expressed and were of the expected molecular weights. Moreover, reprobing with antibodies to the AChR $\alpha$ or $\beta$ subunits demonstrated that, as expected, the CD4-loop chimeras did not assemble together with endogenously expressed receptor subunits (see below).

To assay agrin-induced clustering of the CD4-subunit chimeras, transfected cultures were treated with $\mathrm{z}+$ agrin $(\sim 200 \mathrm{pm}$ for $16 \mathrm{~h}$ ) and immunostained for surface CD4 and AChR. When chimeric proteins corresponding to each of the subunits were examined, only those containing the intracellular loop of the $\beta$ subunit loop were observed to cluster. The CD4- $\beta$ subunit protein aggregated together with the endogenous AChR in $\sim 70 \%$ of expressing myotubes (Fig. 1C; Table 1). In contrast, CD4 and CD4- $\alpha, \gamma, \delta, \varepsilon$ loops all remained diffusely distributed on the myo- 
A

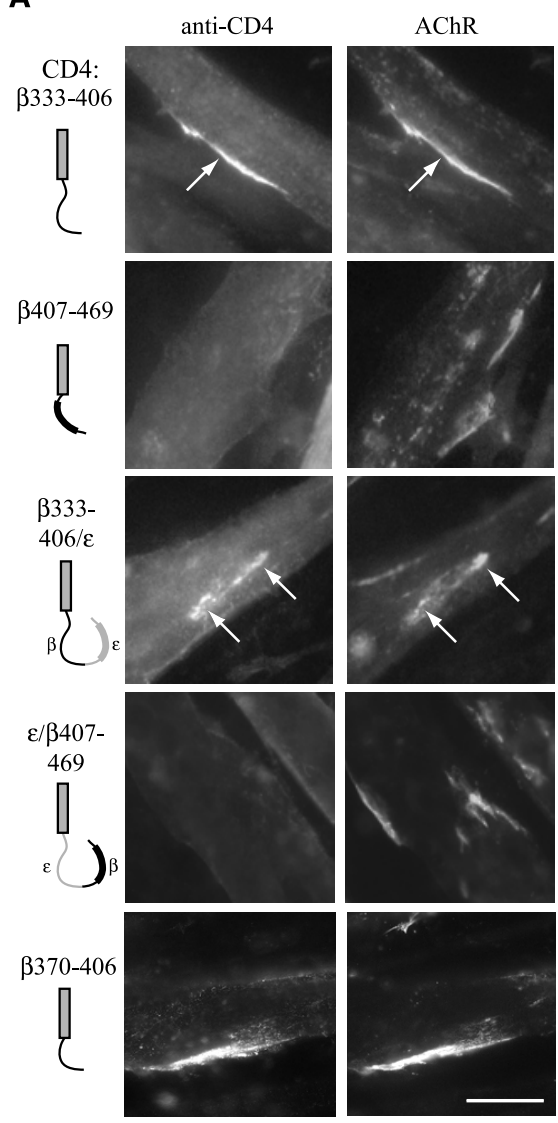

B
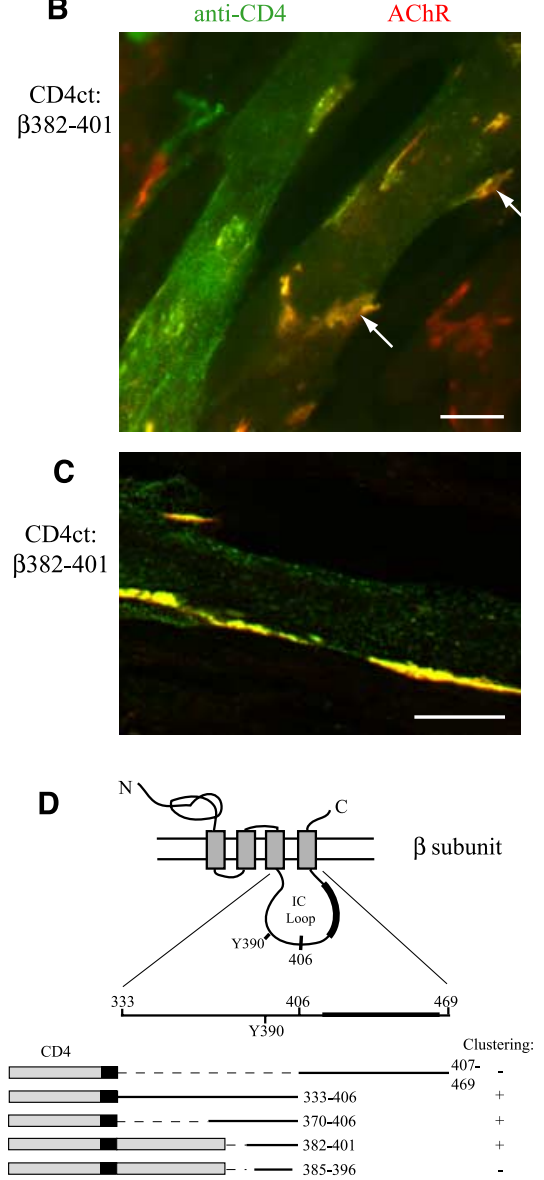

Figure 2. A 20 amino acid motif in the $\beta$ subunit loop is sufficient for clustering. $A, C D 4-\beta$ loop chimeras were generated with either the first (amino acids 333-406) or second halves (407-469) of the loop fused after the CD4 transmembrane domain, and with $\beta 333-406$ or $407-469$ substituted into the corresponding region of $\varepsilon$ loop. Agrin induced clustering of CD4- $\beta 333-406$ and $-\beta 333-406 / \varepsilon$ (arrows) but not $-\beta 407-469$ or $\varepsilon / \beta 407-469$ chimeras. CD4- $\beta 370-406$ also clustered. $B$, CD4-chimeras were also generated with $\beta$ loop fragments fused after the CD4 intracellular tail (CD4ct-). Progressive deletions identified a minimal construct (CD4ct- $\beta 382-401$ ) that clustered efficiently. Scale bar, $20 \mu \mathrm{m} . C, C D 4 c t-\beta 382-401$ colocalized precisely with the AChR in thin optical sections (Apotome slice $\sim 0.9 \mu \mathrm{m}$ ). Scale bar, $20 \mu \mathrm{m}$. D. Schematic showing $\beta$ loop structure and CD4- $\beta$ loop chimeras found to be sufficient for clustering. Y390 denotes a conserved tyrosine phosphorylation site and the thickened line represents the predicted $\alpha$-helix.

tube surface despite normal clustering of the endogenous AChR. In addition, we tested a CD4- $\varepsilon$ loop chimera that included the fourth transmembrane domain and C terminus (CD4- $\varepsilon$ CT) and found that it also failed to cluster in response to agrin treatment (Fig. 1C; Table 1). Thus, in this screen, we find that the long cytoplasmic loop of the $\beta$ subunit loop is sufficient to confer agrin-induced clustering, suggesting that motifs specific for this subunit contribute to AChR localization.

We next defined the region of the $\beta$ subunit loop that mediates clustering by making further deletions or substitutions. First, we tested CD4-chimeras containing the first (amino acids 333406 ) or second halves (aa 407-469) of the $\beta$ loop (Fig. 2). We found that agrin induced robust clustering of CD4- $\beta 333-406$ (in $\sim 75 \%$ of expressing myotubes), compared with essentially no clustering of CD4- $\beta 407-469$ (Fig. 2 A; Table 1 ). Identical results were obtained when we substituted $\beta 333-406$ and $\beta 407-469$ into the corresponding region of $\varepsilon$ loop; only CD4- $\beta 333-406 / \varepsilon$ coclustered with the endogenous AChR (Fig. 2A). We then tested CD4 chimeras with further deletions within the 333-406 region and found clustering of CD4- $\beta 370-406$ but no detectable clustering of smaller fragments fused directly to the CD4 transmembrane domain.

In a second series of chimeric constructs, $\beta$ loop fragments were fused at the end of the CD4 intracellular tail, positioning the fragments at a more natural distance from the plasma membrane $(\sim 40$ aa). Testing of a number of $\beta$ loop deletion fragments (data not shown) identified a minimal $\beta$ loop sequence sufficient for clustering (amino acids 382-401). In myotubes expressing low to moderate levels of CD 4 ct- $\beta 382-401$, this chimera clustered efficiently and colocalized precisely with the AChR in thin optical sections (Figs. 2B, C; Table 1). Chimeras with further deletions such as $\beta 385-396$ clustered only weakly in a few myotubes and additional deletions abolished clustering. Together, these findings identify a 20 aminoacid sequence in the $\beta$ subunit loop that is sufficient for agrin-induced clustering (Fig. 2D).

\section{Regulation of clustering by phosphorylation}

Interestingly, the minimal $\beta$ loop clustering "motif" contains a conserved tyrosine residue (Y390) that is phosphorylated in the AChR after agrin treatment (Wallace et al., 1991) and mutation of this site impairs agrin-induced clustering and anchoring of the AChR (Borges and Ferns, 2001). To test for phosphorylation of this site in the CD4- $\beta$ loop chimeras, they were immunoprecipitated from extracts of control and agrin-treated myotubes, and then immunoblotted with $\beta Y 390$ phosphospecific antibody (Gillespie et al., 1996). We observed agrin-induced phosphorylation of CD4- $\beta$ loop, $\beta 333-406$ and $\beta 333-$ $406 / \varepsilon$ within $1 \mathrm{~h}$ of agrin treatment (Fig. $3 A$ ), before discernable receptor aggregation. We next tested whether phosphorylation was required for clustering by mutating tyrosine 390 to phenylalanine (Y390F); this eliminated phosphorylation without affecting the expression levels of the chimera (Fig. 3B). Intriguingly, mutation of Y390 abolished agrin-induced clustering of all 3 chimeras (CD4- $\beta$ loop, $\beta 333-406, \beta 333-406 / \varepsilon$ ), which remained diffusely distributed despite extensive clustering of the endogenous AChR (Fig. $3 C$; Table 1). These findings demonstrate that agrin-induced phosphorylation of Y390 is essential for clustering of the isolated $\beta$ loop region. Although the $\delta$ subunit loop contains a similar tyrosine (Wagner et al., 1991) that is also phosphorylated by agrin (Mittaud et al., 2001; Mohamed et al., 2001), we found no clustering of CD4- $\delta$ loop and only weak clustering of CD4ct- $\delta 385$ 404 , a fragment analogous to $\beta 382-401$ (Table 1). Similarly, we did not detect clustering of a CD4- $\varepsilon$ loop construct where we introduced a tyrosine residue at this position (data not shown). This suggests that additional, flanking sequences in the $\beta$ loop are required for phosphorylation-dependent aggregation.

If protein interactions with the $\beta$ loop Y390 region are important for AChR clustering, then overexpression of CD4- $\beta$ loop chimeras should inhibit clustering of the endogenous AChR by competing for the requisite binding protein. To test this, we 
transfected myotubes with CD4- $\beta 370-$ 406 and CD4ct- $\beta 382-401$ containing Y390 or Y390F mutations. We selected these chimeras because they were expressed at higher levels than $\mathrm{CD} 4-\beta$ loop or $\beta 333-406$ and encompass just the region sufficient for aggregation. To first assay their expression levels, we sequentially isolated CD4 $\beta$ loop chimeras and then AChR from myotube extracts and immunoblotted with antibodies to CD4 and the $\beta$ subunit loop Y390 region (mAb124) (Fig. 4A). Quantification of the mAb124 immunoblots showed that the CD4- $\beta$ loop chimeras were expressed at levels $\sim 2.5-5$ times that of AChR containing endogenous $\beta$ subunit (Fig. $4 B$ ). We then assayed agrin-induced AChR clustering and found that cluster number was decreased $\sim 25 \%$ in myotubes expressing CD4- $\beta 370-406$ and CD4ct- $\beta 382-401$, compared with control myotubes expressing CD4 (Figs. $4 C, D)(p<0.01$, Student's $t$ test, $n=8)$. This $25 \%$ reduction is an average of all transfected myotubes regardless of expression level; however in myotubes with high levels of CD4- $\beta$ expression, the decrease was more pronounced and the remaining AChR aggregates were sometimes small and fragmented (see highly expressing myotubes in Figs. 2B, 4C). Moreover, the reduction is consistent with the moderate 2.5-5-fold overexpression and the fact that only phosphorylated CD4- $\beta$ loop chimeras can be expected to compete with the AChR. Indeed, no inhibition of AChR clustering was observed in myotubes expressing Y390F versions of CD4- $\beta 370-406$ and CD4ct- $\beta 382-$ 401 , which do not cluster (Fig. $4 C, D$ ). Agrin-induced AChR clustering is inhibited therefore only by $\beta$ loop fragments that aggregate, indicating that this region normally contributes to clustering of the AChR.

Phosphorylation of $\boldsymbol{\beta}$ loop motif regulates rapsyn association Our findings suggest that agrin-regulated, phosphorylationdependent protein interactions with the $\beta$ subunit loop help mediate receptor clustering. One candidate interacting protein is rapsyn, because it is essential for receptor clustering and its interaction with the AChR is increased by agrin (Moransard et al., 2003). To investigate whether rapsyn might bind the phosphorylated $\beta$ subunit, we first treated cultured $\mathrm{C} 2$ myotubes with $\mathrm{z}+$ agrin for one h, isolated surface AChR, and then assayed $\beta$ subunit phosphorylation and rapsyn association by Western blot analysis. Even at this early time point before receptor aggregation, we found that agrin increased the amount of rapsyn coimmunoprecipitated with surface AChR, along with $\beta$ subunit phosphorylation (Fig. 5A), indicating that the events are closely correlated. We then examined whether rapsyn is preferentially associated with phosphorylated AChR, by immunoprecipitating AChR using $\beta$ Y390 phospho-specific antibody and immunoblotting for rapsyn (Fig. $5 B$ ). We found that AChR immunoprecipitated with $\beta Y 390$ phospho-specific antibody had higher levels of associated rapsyn than the remaining surface $\mathrm{AChR}$ isolated using biotinylated BuTX. Because approximately one-half of the total AChR was im-
C

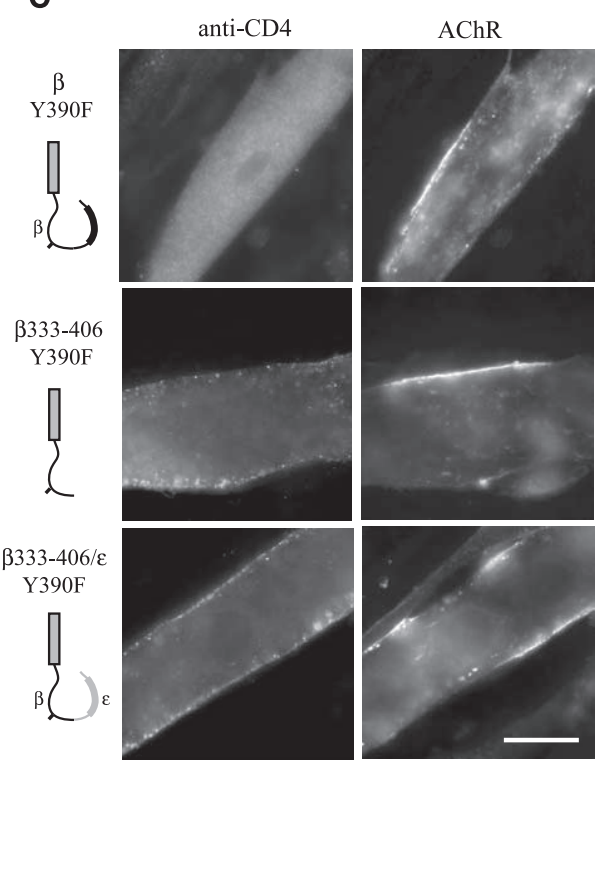

4 IP

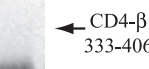

CD4- $\beta$

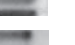

$\underline{\beta 333-406 / \varepsilon}$
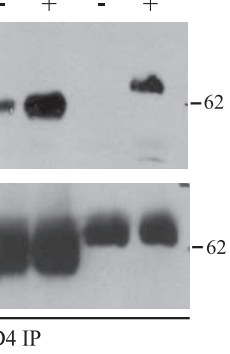

$406 \quad 3333-406$

$390 \mathrm{~F}$

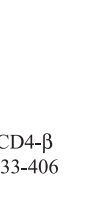

10

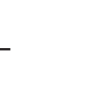

Figure 3. Agrin-induced clustering of CD4- $\beta$ loop chimeras is phosphorylation-dependent. $A, C D 4-\beta$ loop constructs were immunoprecipitated from extracts of control and agrin-treated Sol 8 myotubes $\left(C-\mathrm{Ag}_{4,8}, 1 \mathrm{~nm}, \sim 1 \mathrm{~h}\right)$ and immunoblotted with a reprobing with antibody to CD4. C, Agrin-induced clustering of CD4- $\beta$ loop, $\beta 333-406$ and $\beta 333-406 / \varepsilon$ was abolished by Y390F mutation. Scale bar, $20 \mu \mathrm{m}$.

munoprecipitated with phospho- $\beta$ antibody, this finding shows that more rapsyn is associated with AChR containing phosphorylated $\beta$ subunit compared with nonphosphorylated $\beta$ subunit $(2.3 \pm 0.6$ fold; mean \pm SEM, $n=5$ ).

The findings above show that clustering of CD4- $\beta$ loop is dependent on Y390 phosphorylation and that rapsyn/AChR binding correlates with $\beta$ Y390 phosphorylation. Consequently, we tested whether phosphorylation regulates rapsyn association with the $\beta$ loop motif in muscle cells. C2 myotubes expressing CD4- $3382-401$ Y390 or Y390F were treated with agrin (500 pM) and pervanadate $(0.2 \mathrm{~mm})$ for $1 \mathrm{~h}$ to induce phosphorylation, and the CD4 chimeras were then immunoprecipitated from cell extracts and immunoblotted for associated rapsyn. We found that rapsyn coimmunoprecipitated with CD4- $\beta 382-401$ after agrin/ pervanadate treatment (Fig. $6 \mathrm{~A}$ ), which induced robust phosphorylation of Y390. In contrast, no rapsyn associated with CD4- $\beta 382-$ 401 Y390F chimera, which was expressed at similar levels. Thus, rapsyn binding to the $\beta$ loop motif requires Y390 phosphorylation.

Next, we expressed GST-ct $\beta 382-401$ fusion proteins in bacteria containing an inducible tyrosine kinase and the purified proteins were used in overlay blots that were probed with GSTrapsyn (Fig. 6B). We found that rapsyn bound both GSTct $\beta 382-401$ Y390 and Y390F but not to GST or GST-ct controls. Binding of the rapsyn probe was blocked by excess soluble GSTct $3382-401$ and Coomassie staining confirmed that all GST and GST-fusion proteins were present at similar levels. This confirms that rapsyn binds the $\beta 382-401$ motif, although their interaction was not phosphorylation-dependent in this assay (Y390F $=92 \pm$ $4 \%$ of binding to $\beta 382-401 \mathrm{WT}$; mean \pm SEM, $n=5$ ). One possible explanation stems from our immunoprecipitation ex- 


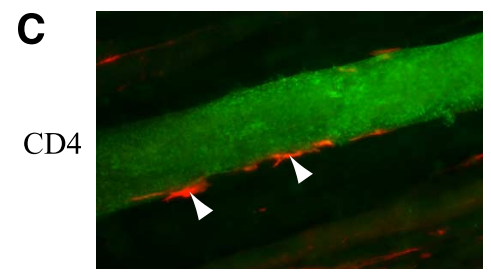

A

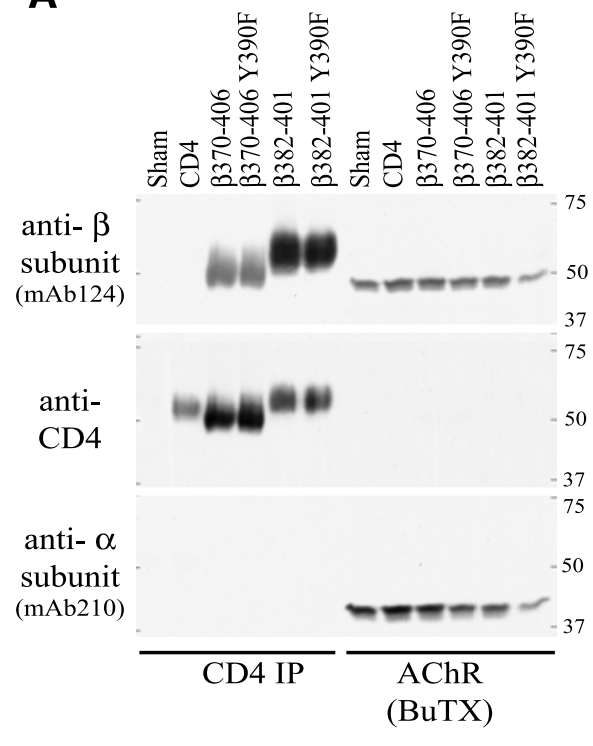

B

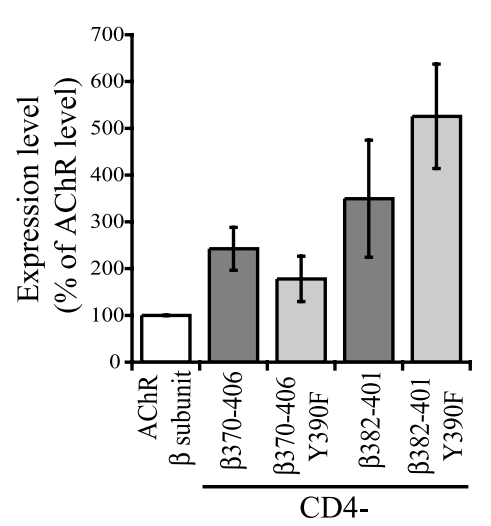

$1382+201$
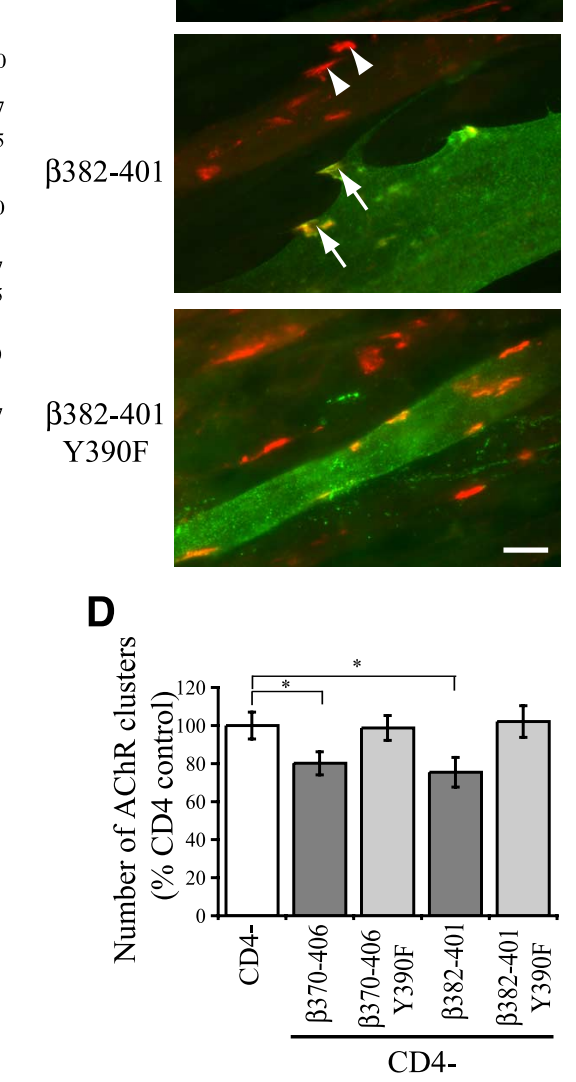

Figure 4. Overexpression of $\mathrm{CD} 4-\beta$ loop chimeras inhibits agrin-induced clustering of the endogenous AChR. $A, C D 4-\beta$ loop chimeras and AChR were sequentially isolated from extracts of transfected Sol8 myotubes using anti-CD4 antibody (CD4 IP) and biotinylated $\alpha$-bungarotoxin (BuTX) respectively. Levels were then compared by immunoblotting with antibodies to CD4 and the $\beta$ loop (mAb124). B, Quantification of the mAb124 immunoblots shows that the CD4- $\beta$ loop constructs were expressed at levels $\sim 2.5-5$ times that of the endogenous $A C h R$, and that mutation of $Y 390$ did not affect expression. Reprobing with antibody to the AChR $\alpha$ subunit also demonstrates that the CD4- $\beta$ loop chimeras do not directly associate with AChR or assemble with the other receptor subunits. C, Immunostaining for surface CD4 (green) and AChR (red) shows that compared with control (CD4 expressing) myotubes, the number of agrin-induced AChR clusters is reduced in myotubes overexpressing CD4ct- $\beta 382-401$. In addition, the remaining AChR clusters were sometimes fragmented and less intensely stained (arrows) compared with those in untransfected or CD4 expressing myotubes (arrowheads). Scale bar, $20 \mu \mathrm{m}$. D, Quantification of the number of agrin-induced AChR clusters in myotubes overexpressing $C D 4$ or $C D 4-\beta$ loop chimeras. Compared with CD4-expressing control myotubes, the number of AChR clusters was significantly reduced $(\sim 25 \%)$ in myotubes expressing CD4- $\beta 370-406$ and CD4ct $-\beta 382-401$ ( $p<0.01$, Student'sttest, $n=8)$. In contrast, no inhibition occurred in myotubes expressing $\beta 370-406$ and $\beta 382-401$ with Y390F mutations.

periments with $\beta$ Y390 phospho-specific antibody, which indicate that the Y390 epitope is not blocked by rapsyn. Thus, phosphorylation may induce a conformational change that facilitates rapsyn binding to adjacent amino acids on the loop, and this may not be apparent in overlay blots in which most protein is denatured and the rapsyn binding site is already exposed. We cannot discount the possibility, however, that another protein mediates the phosphorylation-dependent interaction of rapsyn with the $\beta 382$ 401 motif.

Finally, to investigate further whether $\beta$ subunit phosphorylation regulates rapsyn association with the AChR, we used muscle cell lines derived from wild type and AChR- $\beta^{3 \mathrm{~F} / 3 \mathrm{~F}}$ mice, which have targeted mutations in the three intracellular tyrosines in the $\beta$ subunit (Friese et al., 2007). The AChR- $\beta^{3 \mathrm{~F} / 3 \mathrm{~F}}$ mice lack $\beta$ subunit phosphorylation and have neuromuscular junctions that are simplified and reduced in size, with decreased levels of AChR. After treating wild type and AChR$\beta^{3 \mathrm{~F} / 3 \mathrm{~F}}$ myotubes with agrin for $1 \mathrm{~h}$, surface AChR labeled with biotin-conjugated $\alpha$-bungarotoxin was isolated from cell extracts and immunoblotted for associated rapsyn (Fig. 7A). Interestingly, significantly less rapsyn was associated with AChR in AChR- $\beta^{3 \mathrm{~F} / 3 \mathrm{~F}}$ myotubes compared with wild type, in both untreated and agrin-treated conditions $(p<0.05$ and $0.001, n=6$, ANOVA with Tukey post-test). Moreover, agrin treatment did not increase rapsyn/AChR association significantly in AChR- $\beta^{3 \mathrm{~F} / 3 \mathrm{~F}}$ myotubes, as it did in wild-type myotubes $(\sim 1.8$-fold, $p<0.01, n=6$, ANOVA with Tukey post-test) (Fig. 7B). Thus, phosphorylation of the $\beta$ subunit loop is required for the agrin-regulated increase in rapsyn/AChR association but not for constitutive rapsyn/AChR association.

Potentially, $\beta$ subunit phosphorylation could regulate rapsyn interaction by increasing the number, affinity or stoichiometry of rapsyn/AChR complexes. To begin to distinguish these possibilities, we immunoprecipitated rapsyn and immunoblotted for associated AChR (Fig. 7C). In both wild type and AChR- $\beta^{3 \mathrm{~F} / 3 \mathrm{~F}}$ myotubes, agrin did not increase the amount of AChR associated with immunoprecipitated rapsyn (differences not significant, $n=6$, ANOVA with Tukey post-test) (Fig. 7D). Together, these findings suggest that agrin primarily increases the amount of rapsyn bound to each AChR (which would be evident only in AChR pulldowns), rather than the number or affinity of rapsyn/AChR complexes (which would be evident in both AChR and rapsyn pulldowns).

\section{Discussion}

Our findings identify a novel motif in the long intracellular loop of the AChR $\beta$ subunit that is sufficient for targeting to postsynaptic AChR clusters. In our screen, the $\beta$ loop sequence was the sole region of the AChR sufficient for postsynaptic localization and its addition to CD4 or substitution into $\varepsilon$ loop resulted in efficient agrininduced clustering. The $\beta$ loop "clustering" domain is centered on a tyrosine residue (Y390) and surrounding sequence of $\sim 20$ aa that is highly conserved between species (Fig. $8 A$ ). Moreover, $\beta$ Y390 is phosphorylated in synaptic AChR and is a known site of agrin-induced phosphorylation (Wallace et al., 1991; Borges and Ferns, 2001). Consistent with this, we found that agrin induced Y390 phosphorylation in CD4- $\beta$ loop chimeras, and that mutation of Y390F abolished aggregation; thus, protein interactions with this $\beta$ loop region are phosphorylation-dependent. Interestingly, we found that $\delta$ loop did not cluster significantly despite containing a similar tyrosine residue that is also phosphorylated 
in synaptic AChR. Thus, although agrin induces phosphorylation of both subunits (Wallace et al., 1991; Ferns et al., 1996; Borges and Ferns, 2001, Mittaud et al., 2001; Mohamed et al., 2001), our findings suggest that $\beta$ and $\delta$ phosphorylation is functionally distinct. Although $\beta$ subunit phosphorylation is clearly implicated in AChR localization, $\delta$ loop phosphorylation is likely involved in some other aspect of channel function such as recruiting adaptor or signaling proteins.

As the $\beta$ loop motif is sufficient for clustering of chimeric proteins and mutation of $\beta$ Y390 impairs clustering of intact AChR (Borges and Ferns, 2001), phosphorylation must regulate protein interactions involved in AChR localization. Somewhat unexpectedly, our findings demonstrate that the $\beta$ loop motif forms a regulated binding site for rapsyn. First, we found that agrin increased rapsyn/AChR association in parallel with $\beta$ subunit phosphorylation, and that rapsyn was preferentially associated with phosphorylated AChR. Second, rapsyn bound the $\beta$ loop Y390 region (20 aa) in overlay blots, although binding was not phosphorylation-dependent in this assay. One possible explanation is that Y390 phosphorylation induces a conformational change (Phan-Chan-Du et al., 2003) that promotes rapsyn binding to adjacent residues and this is probably not apparent in overlay blots because most protein is denatured. Alternatively, another muscle protein might form a tertiary complex with rapsyn and the $\beta$ loop and mediate their phosphorylation-dependent interaction. Third, in coimmunoprecipitation experiments from muscle cells, rapsyn associated with CD4- $\beta 382-401$ in a strictly phosphorylation-dependent manner. Fourth, agrin increased rapsyn binding to wild type AChR but not to AChR- $\beta^{3 \mathrm{~F} / 3 \mathrm{~F}}$ that lacks $\beta$ phosphorylation. Together, this provides strong evidence that agrin-induced phosphorylation regulates rapsyn binding to the $\beta$ loop Y390 region.

In addition to regulated binding to $\beta$ loop, rapsyn clearly binds other site(s) on the AChR. Rapsyn still coimmunoprecipitates with AChR- $\beta^{3 \mathrm{~F} / 3 \mathrm{~F}}$, although in lower amounts than with wild type AChR, and colocalizes with AChR at the NMJ of $\mathrm{AChR}-\beta^{3 \mathrm{~F} / 3 \mathrm{~F}}$ mice (Friese et al., 2007). Consistent with this, previous studies have shown that rapsyn interacts with all AChR subunits in heterologous cells (Maimone and Merlie, 1993; Huebsch and Maimone, 2003), and we found that this interaction occurs via the $\alpha$-helical domain in the large intracellular loop and is agrinindependent (Y. Lee, J. Rudell, and M.
A

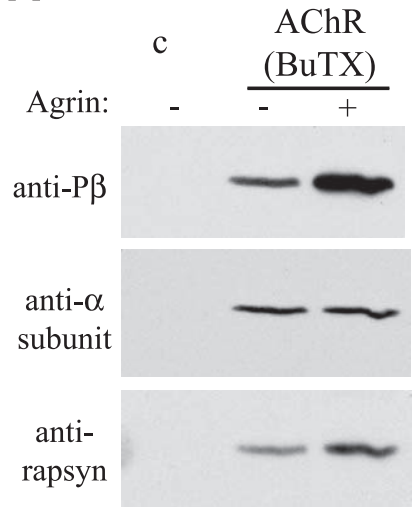

B

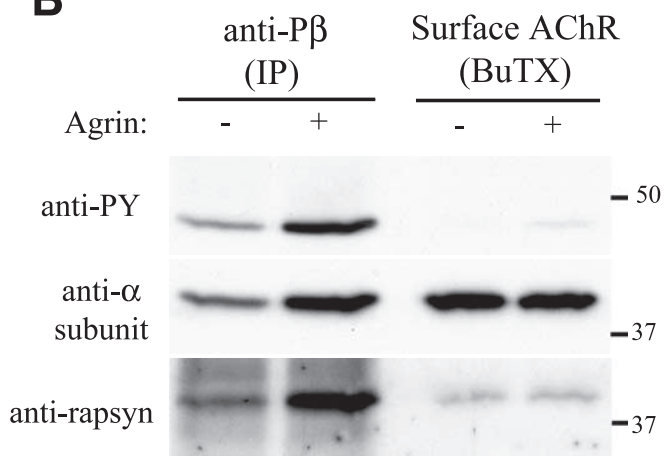

Figure 5. Rapsyn is preferentially associated with phosphorylated AChR. A, Surface AChR were isolated from control and agrin-treated Sol8 myotubes using biotinylated $\alpha$-bungarotoxin (BuTX) and immunoblotted with $\beta Y 390$ phospho-specific antibody, anti- $\alpha$ subunit antibody (mAb210) and anti-rapsyn antibody (B6766). Agrin treatment for $1 \mathrm{~h}\left(\mathrm{C}_{-} \mathrm{Ag}_{4,8}, 200 \mathrm{pm}\right)$ increased both the amount of rapsyn that coimmunoprecipitated with the $A C h R$ and $\beta$ subunit phosphorylation. $B$, Phosphorylated $A C h R$ was immunoprecipitated with phospho- $\beta Y 390$ antibody, and then residual surface AChR was isolated using biotinylated $\alpha$-BuTX. Immunoblotting with anti-PY antibodies shows that most AChR containing phosphorylated $\beta$ subunit was immunoprecipitated with phospho-specific $\beta Y 390$ antibody, and reprobing with mAb210 shows that $\sim 1 / 2$ of the total surface receptor is phosphorylated. Immunoblotting for rapsyn indicates that more rapsyn is associated with phosphorylated than nonphosphorylated AChR.

\section{A}

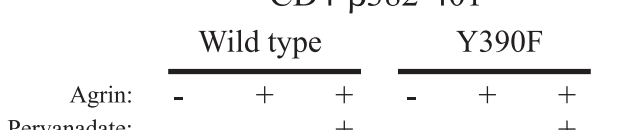

$\begin{array}{rllllll}\text { Agrin: } & - & + & + & - & + & + \\ \text { Pervanadate: } & - & - & + & - & - & +\end{array}$
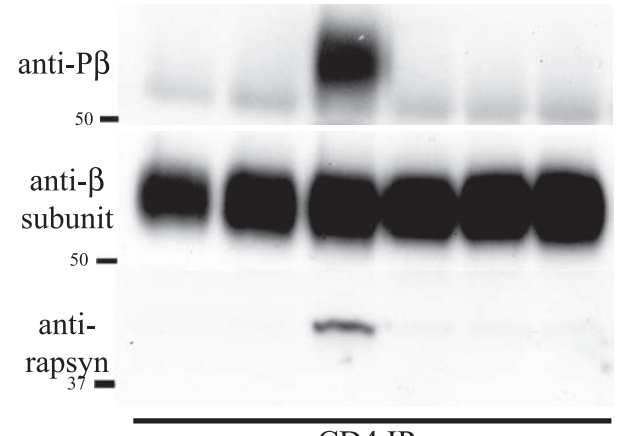

CD4 IP

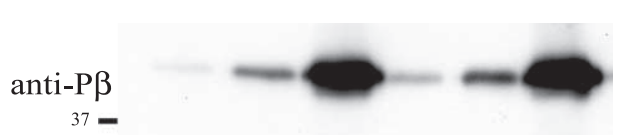

$37-$

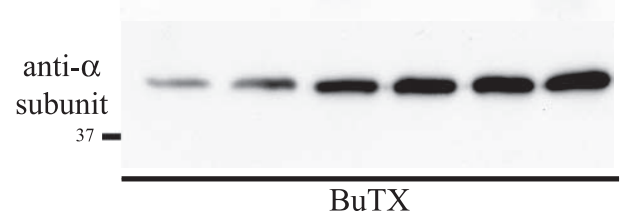

B

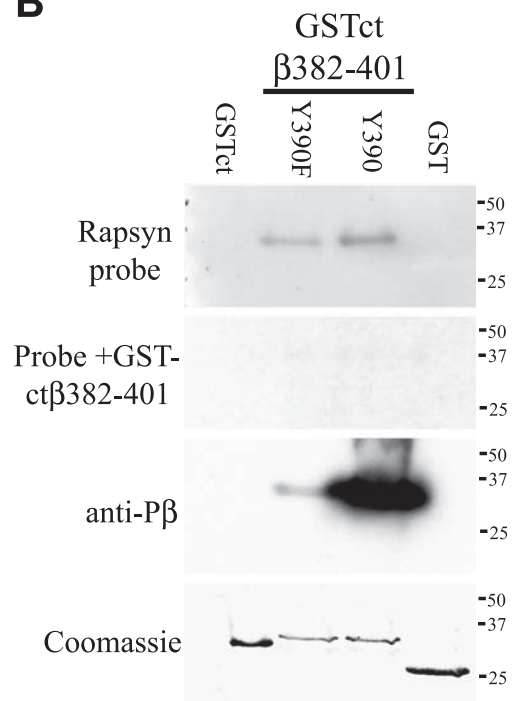

Figure 6. Rapsyn binds $\beta$ loop 382-401 in a phosphorylation-dependent manner. A, CD4ct- $\beta 382-401$ chimeras were immunoprecipitated from extracts of control or agrin plus pervanadate-treated myotubes ( 500 рм agrin, 0.2 mм pervanadate; $1 \mathrm{~h}$ ) and immunoblotted with anti-rapsyn antibody (B5668). Rapsyn associated with wild-type CD4ct- $\beta 382-401$ only after agrin plus pervanadate treatment that induced robust phosphorylation of Y390. No rapsyn associated with Y390F CD4ct- $\beta 382-401$ that was expressed at similar levels but lacked phosphorylation $(n=4)$. Sequential isolation and immunoblotting of the AChR showed that agrin plus pervanadate induced significantly greater $\beta$ subunit phosphorylation than agrin alone. $B$, GST fusion proteins immobilized on membranes were probed with $5 \mu \mathrm{g} / \mathrm{ml}$ GST-rapsyn and bound protein detected by immunoblotting with antirapsyn antibody (B5668). Rapsyn bound specifically to GSTct- $\beta 382-401$ Y390 and Y390F but not to GST or GSTct controls, and binding was eliminated by incubating the GST-rapsyn probe together with $25 \mu \mathrm{g} / \mathrm{ml}$ soluble GSTct- $\beta 382-401$. Coomassie staining shows that all fusion proteins were present at similar levels $(n=5)$. 
A
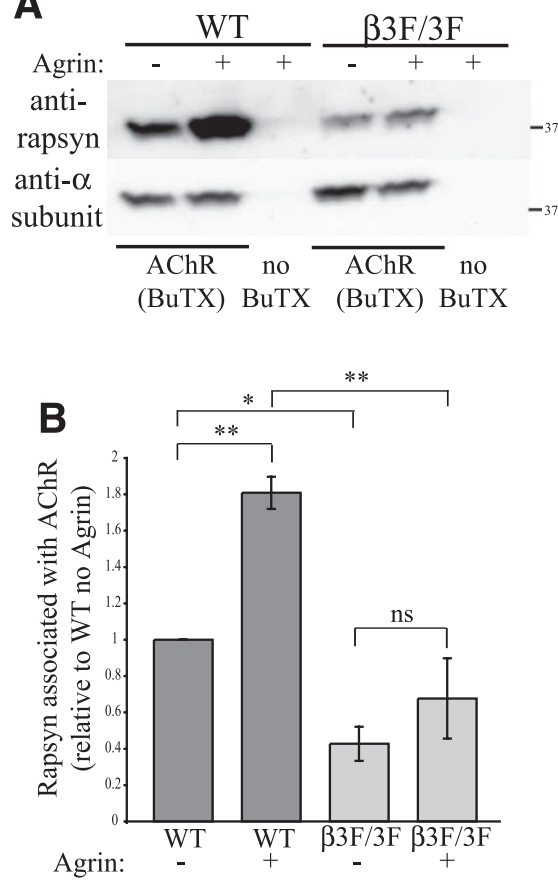

C

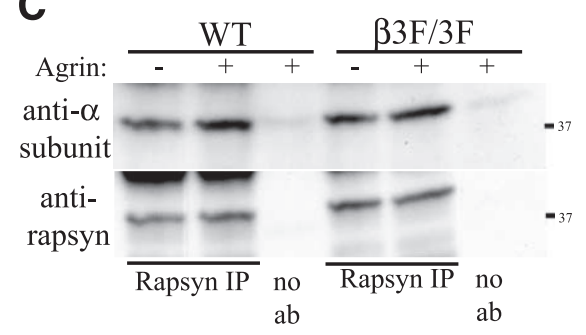

D

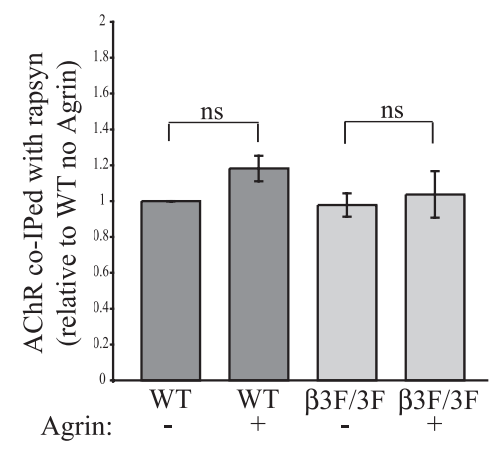

Figure 7. Phosphorylation of $\beta$ loop increases the stoichiometry of rapsyn binding to AChR. $\boldsymbol{A}, \boldsymbol{B}$, Surface AChR was pulled down from wild type and AChR- $\beta^{3 \mathrm{~F} / 3 \mathrm{~F}}$ myotubes using biotinylated $\alpha$-BuTX and the isolates immunoblotted with anti- $\alpha$ subunit (mAb210) and anti-rapsyn antibody (B6766). Agrin increased the amount of rapsyn associated with wild type AChR ( 1.8-fold, $p<0.01, n=6$, ANOVA with Tukey post-test) but not $A C h R-\beta^{3 \mathrm{~F} / 3 \mathrm{~F}}$ (ns = not significant). In addition, less rapsyn was associated with $A C h R-\beta^{3 F / 3 F}$ compared with wild type $A C h R$ in both control and agrin-treated conditions $(p<0.05$ and 0.001 , respectively, ANOVA with Tukey post-test). C, D, Rapsyn was immunoprecipitated from wild type and AChR- $\beta^{3 \mathrm{~F} / 3 \mathrm{~F}}$ myotubes and the isolates immunoblotted with anti- $\alpha$ subunit (mAb210) and anti-rapsyn antibody (B6766). Agrin did not affect the amount of wild type or $\beta^{3 \mathrm{~F} / 3 \mathrm{~F}}$ AChR associated with rapsyn ( $n=6$, differences not significant, ANOVA with Tukey post-test). Thus, agrin-induced $\beta$ phosphorylation increases the ratio of rapsyn to AChR, but not AChR to rapsyn, suggesting that it primarily increases stoichiometry of rapsyn binding to each $A C h R$.

Ferns, submitted). We propose, therefore, that rapysn binds at two distinct sites on the AChR: constitutive binding to the $\alpha$-helical domain of one or more subunit loops and regulated binding to the $\beta$ subunit loop Y390 region.

How does regulated rapsyn binding to the AChR $\beta$ subunit loop contribute to AChR localization and what is its function? A possible molecular mechanism is suggested by two key findings. First, we found that more rapsyn was associated with phosphorylated than nonphosphorylated AChR and that less rapsyn was associated with $A C h R-\beta^{3 \mathrm{~F} / 3 \mathrm{~F}}$ versus wild type AChR. Second, we found that agrin increased the amount of rapsyn coisolated with AChR by 1.8 -fold, but the amount of AChR coimmunoprecipitated with rapsyn by only 1.2 -fold. These findings are most consistent with phosphorylation increasing the ratio of rapsyn to $\mathrm{AChR}$, so that in addition to one molecule of rapsyn bound constitutively to the receptor, a second molecule of rapsyn becomes bound to the phosphorylated $\beta$ loop. Indeed, estimates of the stoichiometry of rapsyn to AChR in Torpedo synaptic membranes range from 1:1-2:1 (Sealock, 1982; LaRochelle and Froehner, 1986), and a 4.6 Angstrom structure of AChR/rapsyn complexes derived from electron images of Torpedo membranes shows a twofold symmetry for rapsyn (Miyazawa et al., 1999), implying 2 rapsyn molecules associate with a single AChR. Recent studies on the developing rodent NMJ also demonstrate that the rapsyn to $\mathrm{AChR}$ ratio increases during development (Gervásio et al., 2007), and that rapsyn overexpression can increase rapsyn levels even at adult synapses (Gervasio and Phillips, 2005). Rapsyn turnover is also faster than AChRs, allowing for regulated

and dynamic binding to the receptor (Bruneau and Akaaboune, 2007). Together, these findings suggest a model in which agrin-induced phosphorylation of the $\beta$ subunit increases the number of rapsyn molecules binding each AChR (see Fig. $8 B$ ). One consequence could be to increase AChR packing density and stability, as reported for rapsyn overexpression at developing rat NMJs (Gervásio et al., 2007). Another possibility is that additional rapsyn binding might anchor $\mathrm{AChR}$ more stably to the postsynaptic cytoskeleton (Fig. $8 B$ ), as we have shown previously that mutation of $\beta$ Y390 decreases linkage of AChR to the detergent-resistant cytoskeleton and impairs its aggregation in muscle cells (Borges and Ferns, 2001). Thus, in $\mathrm{AChR}-\beta^{3 \mathrm{~F} / 3 \mathrm{~F}}$ mice that lack $\beta$ subunit phosphorylation, AChR is presumably localized at the NMJ because one molecule of rapsyn can bind to AChRs independent of $\beta$ subunit phosphorylation. Failure of a second molecule of rapsyn to bind mutant AChRs may impair anchoring and stability of the receptor, however, leading to the decreased density and number of AChRs and other defects in synaptic maturation (Friese et al., 2007).

In summary, our findings identify a motif in the $\beta$ subunit intracellular loop that is sufficient for clustering and show that phosphorylation of this motif induces more rapsyn binding to each AChR. We propose, therefore, that rapsyn interacts both in a regulated and constitutive manner with the AChR, with each mode of interaction having distinct functions that combine to localize the AChR at appropriate levels at the NMJ. Phosphorylation-dependent binding of rapsyn also provides a mechanism to regulate AChR localization at developing and mature NMJs. During initial synaptogenesis, agrin-induced binding of additional rapsyn to the $\beta$ subunit loop could selectively stabilize innervated AChR clusters, and at mature synapses, it could regulate AChR stability and thus modulate synaptic strength.

\section{References}

Banks GB, Fuhrer C, Adams ME, Froehner SC (2003) The postsynaptic submembrane machinery at the neuromuscular junction: requirement for rapsyn and the utrophin/dystrophin-associated complex. J Neurocytol 32:709-726.

Borges LS, Ferns M (2001) Agrin-induced phosphorylation of the acetylcholine receptor regulates cytoskeletal anchoring and clustering. J Cell Biol 153:1-12

Bruneau E, Akaaboune M (2007) The dynamics of the rapsyn scaffolding protein at individual acetylcholine receptor clusters. J Biol Chem 282:9932-9940.

Burden SJ (1985) The subsynaptic 43-kDa protein is concentrated at developing nerve-muscle synapses in vitro. Proc Natl Acad Sci USA 82:8270-8273.

Ferns M, Deiner M, Hall Z (1996) Agrin-induced acetylcholine receptor clustering in mammalian muscle requires tyrosine phosphorylation. J Cell Biol 132:937-944.

Frangioni JV, Neel BG (1993) Solubilization and purification of enzymatically active glutathione S-transferase (pGEX) fusion proteins. Anal Biochem 210:179-187.

Friese MB, Blagden CS, Burden SJ (2007) Synaptic differentiation is defec- 
tive in mice lacking acetylcholine receptor beta-subunit tyrosine phosphorylation. Development 134:4167-4176.

Froehner SC, Gulbrandsen V, Hyman C, Jeng AY, Neubig RR, Cohen JB (1981) Immunofluorescence localization at the mammalian neuromuscular junction of the Mr 43,000 protein of Torpedo postsynaptic membranes. Proc Natl Acad Sci U S A 78:5230-5234.

Froehner SC, Luetje CW, Scotland PB, Patrick J (1990) The postsynaptic 43K protein clusters muscle nicotinic acetylcholine receptors in Xenopus oocytes. Neuron 5:403-410.

Gautam M, Noakes PG, Mudd J, Nichol M, Chu GC, Sanes JR, Merlie JP (1995) Failure of postsynaptic specialization to develop at neuromuscular junctions of rapsyn-deficient mice. Nature 377:232-236.

Gautam M, Noakes PG, Moscoso L, Rupp F, Scheller RH, Merlie JP, Sanes JR (1996) Defective neuromuscular synaptogenesis in agrin-deficient mutant mice. Cell 85:525-535.

Gervasio OL, Phillips WD (2005) Increased ratio of rapsyn to ACh receptor stabilizes postsynaptic receptors at the mouse neuromuscular synapse. J Physiol 562:673-685.

Gervásio OL, Armson PF, Phillips WD (2007) Developmental increase in the amount of rapsyn per acetylcholine receptor promotes postsynaptic receptor packing and stability. Dev Biol 305:262-275.

Gillespie SK, Balasubramanian S, Fung ET, Huganir RL (1996) Rapsyn clusters and activates the synapse-specific receptor tyrosine kinase MuSK. Neuron 16:953-962.

Huebsch KA, Maimone MM (2003) Rapsynmediated clustering of acetylcholine receptor subunits requires the major cytoplasmic loop of the receptor subunits. J Neurobiol 54:486-501.

LaRochelle WJ, Froehner SC (1986) Determination of the tissue distributions and relative concentrations of the postsynaptic $43 \mathrm{kDa}$ protein and the acetylcholine receptor in Torpedo. J Biol Chem 261:5270-5274.

Lee Y, Rudell J, Yechikhov S, Taylor R, Swope S, Ferns M (2008) Rapsyn carboxyl terminal domains mediate muscle specific kinase-induced phosphorylation of the muscle acetylcholine receptor. Neuroscience 153:997-1007.

Lin Y, Rudell J, Yechikhov S, Taylor R, Swope S, Ferns M (2008) Rapsyn carboxyl terminal domains mediate muscle specific kinase-induced phosphorylation of the muscle acetylcholine receptor. Neuroscience 153:997-1007.

Lin W, Dominguez B, Yang J, Aryal P, Brandon EP, Gage FH, Lee KF (2005) Neurotransmitter acetylcholine negatively regulates neuromuscular synapse formation by a Cdk5-dependent mechanism. Neuron 46:569-579.

Maimone MM, Merlie JP (1993) Interaction of the $43 \mathrm{kd}$ postsynaptic protein with all subunits of the muscle nicotinic acetylcholine receptor. Neuron 11:53-66.

Misgeld T, Kummer TT, Lichtman JW, Sanes JR (2005) Agrin promotes synaptic differentiation by counteracting an inhibitory effect of neurotransmitter. Proc Natl Acad Sci U S A 102:11088-11093.

Mittaud P, Marangi PA, Erb-Vögtli S, Fuhrer C (2001) Agrin-induced activation of acetylcholine receptor-bound Src family kinases requires Rapsyn and correlates with acetylcholine receptor clustering. J Biol Chem 276:14505-14513.

Miyazawa A, Fujiyoshi Y, Stowell M, Unwin N (1999) Nicotinic acetylcholine receptor at 4.6 A resolution: transverse tunnels in the channel wall. J Mol Biol 288:765-786.

Mohamed AS, Rivas-Plata KA, Kraas JR, Saleh SM, Swope SL (2001) Src-class kinases act within the agrin/MuSK pathway to regulate acetylcholine receptor phosphorylation, cytoskeletal anchoring, and clustering. J Neurosci 21:3806-3818.

Moransard M, Borges LS, Willmann R, Marangi PA, Brenner HR, Ferns MJ, Fuhrer C (2003) Agrin regulates rapsyn interaction with surface acetylcholine receptors, and this underlies cytoskeletal anchoring and clustering. J Biol Chem 278:7350-7359.

Noakes PG, Phillips WD, Hanley TA, Sanes JR, Merlie JP (1993) 43K pro-

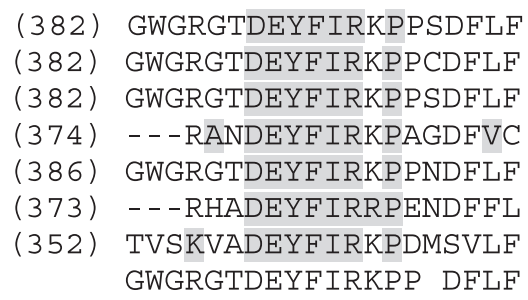

TWRGTDEYFIRKPP DFLF

(1)

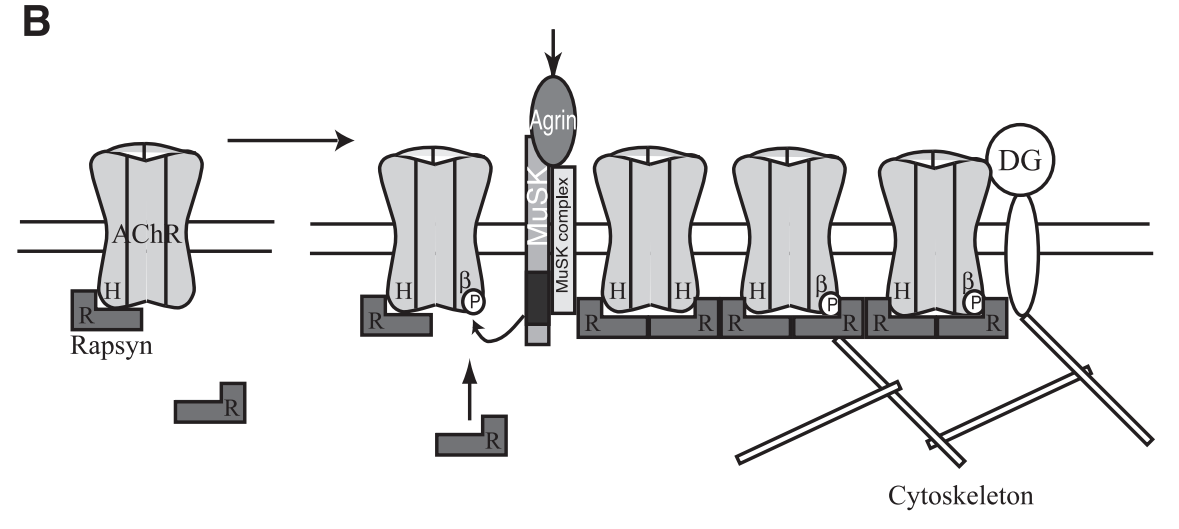

Cytoskeleton

Figure 8. Working model for how agrin-induced phosphorylation of $A C h R \beta$ subunit regulates rapsyn association and receptor tion. $\boldsymbol{A}$, Alignment showing that the $\beta$ subunit motif sufficient for clustering is highly conserved between species. $\boldsymbol{B}, 0$ ur induces binding of additional rapsyn to the $\beta 382-401$ motif. This increase in stoichiometry may increase the efficiency of AChR and also anchor and stabilize the receptor via interactions with dystroglycan (DG) or cytoskeletal proteins. Both forms of rapsyn binding contribute to localizing the AChR at high density in the postsynaptic membrane.

tein and acetylcholine receptors colocalize during the initial stages of neuromuscular synapse formation in vivo. Dev Biol 155:275-280.

Okada K, Inoue A, Okada M, Murata Y, Kakuta S, Jigami T, Kubo S, Shiraishi H, Eguchi K, Motomura M, Akiyama T, Iwakura Y, Higuchi O, Yamanashi Y (2006) The muscle protein Dok-7 is essential for neuromuscular synaptogenesis. Science 312:1802-1805.

Phan-Chan-Du A, Hemmerlin C, Krikorian D, Sakarellos-Daitsiotis M, Tsikaris V, Sakarellos C, Marinou M, Thureau A, Cung MT, Tzartos SJ (2003) Solution conformation of the antibody-bound tyrosine phosphorylation site of the nicotinic acetylcholine receptor beta-subunit in its phosphorylated and nonphosphorylated states. Biochemistry 42:7371-7380.

Phillips WD, Kopta C, Blount P, Gardner PD, Steinbach JH, Merlie JP (1991) ACh receptor-rich membrane domains organized in fibroblasts by recombinant 43-kilodalton protein. Science 251:568-570.

Sanes JR, Lichtman JW (2001) Induction, assembly, maturation and maintenance of a postsynaptic apparatus. Nat Rev Neurosci 2:791-805.

Sealock R (1982) Cytoplasmic surface structure in postsynaptic membranes from electric tissue visualized by tannic-acid-mediated negative contrasting. J Cell Biol 92:514-522.

Sheng M, Pak DT (2000) Ligand-gated ion channel interactions with cytoskeletal and signaling proteins. Annu Rev Physiol 62:755-778.

Strochlic L, Cartaud A, Cartaud J (2005) The synaptic muscle-specific kinase (MuSK) complex: New partners, new functions. Bioessays 27:1129-1135.

Wagner K, Edson K, Heginbotham L, Post M, Huganir RL, Czernik AJ (1991) Determination of the tyrosine phosphorylation sites of the nicotinic acetylcholine receptor. J Biol Chem 266:23784-23789.

Wallace BG (1989) Agrin-induced specializations contain cytoplasmic, membrane, and extracellular matrix-associated components of the postsynaptic apparatus. J Neurosci 9:1294-1302.

Wallace BG, Qu Z, Huganir RL (1991) Agrin induces phosphorylation of the nicotinic acetylcholine receptor. Neuron 6:869-878.

Wang J, Jing Z, Zhang L, Zhou G, Braun J, Yao Y, Wang ZZ (2003) Regulation of acetylcholine receptor clustering by the tumor suppressor APC. Nat Neurosci 6:1017-1018. 